\title{
A IGREJA CATÓLICA E O MEIOAMBIENTE: CONSIDERAÇÕES SOBRE OS TEXTOS-BASE DA CAMPANHA DA FRATERNIDADE A PARTIR DO CONCÍLIO VATICANO II
}

NAHRA, Jorge João Aparecido. Mestre em Desenvolvimento Regional e Meio Ambiente do Centro Universitário de Araraquara - Uniara/Araraquara-SP.

GALLO, Zildo. Prof. Dr. do Mestrado em Desenvolvimento Regional e Meio Ambiente - Uniara. SOSSAE, Flávia Cristina. Profa. Dra. do Mestrado em Desenvolvimento Regional e Meio Ambiente - Uniara. BAPTISTA, Katia Aparecida. Profa. Dra. da UNESP/Araraquara-SP.

\section{ReSUMo}

A Campanha da Fraternidade surgiu durante o Concílio Vaticano II. A sua realização demonstra uma preocupação como despertar do ser humano para os seus problemas existenciais. Nesse sentido, o objetivo da Campanha da Fraternidade é promover uma reflexão sobre temas importantes para a vida do ser humano, com o intuito de mudar o seu agir, através do princípio do cuidado, diante de algumas realidades que são necessárias para o bom relacionamento e sobrevivência de cada um. O objetivo principal do estudo é identificar a abordagem sobre a questão do meio ambiente nos textos-base das Campanhas da Fraternidade da Igreja Católica do Brasil, à luz da Doutrina Social da mesma, dos documentos do CELAM e CNBB. Os objetivos específicos são: compreender a proposta da ética do cuidado; apresentar as orientações da Igreja em relação ao meio ambiente a partir da Doutrina Social e dos documentos do CELAM e CNBB; identificar as propostas ou ensinamentos sobre o meio ambiente nos textos-base das Campanhas da Fraternidade de 1979 a 2011. A metodologia fundamenta-se nas análises de ampla pesquisa documental, destacando os textos das Campanhas da Fraternidade, as Encíclicas Papais, entre outros documentos da Igreja. Considerando o tamanho e a abrangência da Igreja Católica, sua contribuição para a questão da preservação do meio ambiente é relevante.

Palavras-chave: Campanha da Fraternidade; Meio ambiente; Igreja Católica.

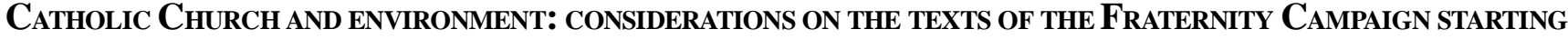
Since Vatican Council II

\section{Abstract}

The Fraternity Campaign emerged during the Vatican Council II. Its implementation demonstrates a concern with the awakening of human beings to their existential problems. In this sense, the purpose of the Fraternity campaign is to promote reflection about important issues for human lives, in order to change their actions, based on the principle of care, when facing some realities that are necessary for good relations and for each one's survival. The main objective of the study is to identify the approach on environmental issues in the basic texts of Fraternity Campaigns of the Catholic Church in Brazil in the light of the Social Doctrine and CELAM and CNBB documents. The specific objectives are: to understand the proposal of care ethics; to present church guidelines concerning environment based on the Social Doctrine and the CELAM and CNBB documents; to identify the proposals or teachings about the environment in the basic texts of the Fraternity Campaigns from 1979 to 2011. The methodology is based on the analyses of extensive documentary research, emphasizing the texts of Fraternity Campaigns, the Papal Encyclicals and other Church documents. Considering the size and scope of the Catholic Church, its contribution to the issue of environmental preservation is relevant. 
KEYwords: Fraternity Campaign; Environment; Catholic Church.

\section{INTRODUÇÃO}

O presente artigo baseia-se na dissertação de mestrado de Jorge João Aparecido Nahra, sacerdote da Igreja Católica, intitulada Ética e meio ambiente: considerações sobre os textos-base das campanhas da fraternidade de 1979 e 2011, realizada sob a orientação do Professor Doutor Zildo Gallo. Esta pesquisa também contou coma contribuição importante das professoras doutoras Kátia Aparecida Baptista e Flávia Cristina Sossae nas bancas de qualificação e defesa.

A Campanha da Fraternidade sempre foi marcada por trabalhar temas caros à vida humana. A utilização do método "ver-julgar e agir" mostra uma preocupação da Igreja do Brasil em oferecer pressupostos básicos para a sociedade brasileira, a fim de mudar o relacionamento quer com temas da própria Igreja, quer com temas sociais que traduzem uma ética centrada na vida.

Discute-se muito, hoje, sobre o "agir" de cada ser humano relacionado com o meio ambiente, mas se percebe uma falta de formação da consciência sobre esse agir. Muitas vezes, as coisas ficam somente atreladas a comemorações, seguindo um ritual de calendário que, na maioria dos casos, não é eficaz nem eficiente.

No contexto da filosofia, a ética seria o ramo que lida com a compreensão que sustenta as bases da moralidade social e da vida individual. Trata-se de uma reflexão sobre o valor das ações sociais consideradas tanto no âmbito coletivo como individual. Areflexão ética realiza-se tendo em vista o ethos, que significa a realidade, o contexto em que vivemos, e ainda a casa, a morada humana. Assim, o ser humano é um ser ético, ou seja, nossa formação se completa com a educação ética. Nesse aspecto, a ética, para se desenvolver, necessita que o homem vivesse uma "liberdade responsável".

Por isso, ao apresentarmos os aspectos conceituais e apontamentos da ética na história, realizamos um percurso reflexivo que mostra o desenvolvimento do agir ético, perpassando os diversos momentos da vida humana. Inicia com os gregos e passa pelos períodos históricos da filosofia, isto é, antiguidade, modernidade e contemporaneidade, destacando os principais pensamentos filosóficos sobre a ética desses períodos, chegando até hoje, quando o pensamento se volta mais para a ética do cuidado, conforme observa o teólogo e filósofo Leonardo Boff (1999, p. 25) quando fala sobre uma nova filosofia que deve ser holística, ecológica e espiritual. Para ele, essa espiritualidade também deve sustentar-se numa ética de responsabilidade, de solidariedade e de compaixão. Para Boff (2003, p. 66), o bem comum não pode ser concebido apenas a partir do ser humano (antropocentrismo); a natureza e os seus ecossistemas devem ser considerados; o bem comum deve ser de toda a comunidade terrestre com quem ele compartilha o seu destino.

No período recente, em virtude do desenvolvimento econômico da humanidade, a partir do crescimento da indústria, que dá um salto por volta do ano 1750 e continua ininterruptamente até os dias de hoje, que cria problemas ambientais graves, com destaque para o aquecimento global, entre muitos outros, estamos vivendo situações que comprometem o meio ambiente como um todo e afetam a qualidade de vida dos seres humanos e de todos demais os seres do planeta.

A Igreja Católica é uma instituição milenar que está inserida na sociedade, e tem como primeira tarefa a evangelização dos povos, ou seja, o despertar da fé mediante a Boa-Nova de Cristo que é o Evangelho. Tendo em vista os problemas que afetam o meio ambiente, o propósito desta pesquisa é apresentar a colaboração da Igreja no debate, no diálogo e nas proposições sobre o assunto, que aflige a sociedade como um todo. O diálogo da Igreja como mundo passa pela realização do Concílio Vaticano II, que, através de seus documentos, inicia a abordagem sobre o meio ambiente. Outros documentos que irão trabalhar a questão ambiental são as cartas encíclicas papais, bem como os documentos das Conferências Gerais do Episcopado Latino-Americano e do Caribe, e da 
Conferência Nacional dos Bispos do Brasil.

A pesquisa deste trabalho se baseou no levantamento de documentos da Igreja que tratam do meio ambiente, bem como os textos-base das Campanhas da Fraternidade que versam sobre o mesmo assunto, e sobre a questão da ética do cuidado como referencial teórico. Há que se destacar aqui a contribuição do filósofo e ecólogo Hans Jonas para essa nova ética, pois ele introduz, em $O$ Princípio Responsabilidade (1995), uma nova dimensão para a responsabilidade humana, que vai além da responsabilidade para com os semelhantes. Ele estende a responsabilidade para toda a natureza. Assim, a vulnerabilidade da natureza sempre deve ser considerada. Não se trata de defender a natureza como autodefesa, para evitar apenas o sofrimento humano; é necessário pensar numa ética para toda a natureza.

Jonas (2004, p. 11) argumenta em O Princípio Vida que, em suas formas mais elementares, o orgânico prefigura o espiritual e que, também em suas formas mais elevadas, o espírito permanece como parte do orgânico. No epílogo da sua obra ele conclui que apenas "uma ética fundamentada na amplitude do ser, e não apenas na singularidade ou peculiaridade do ser humano, é que pode ser de importância no universo das coisas" (JONAS, 2004, p. 272).

A ecologia filosófica, ecologia profunda, para o físico e ecólogo Fritjof Capra (2005, p. 20), diferenciase da ecologia rasa. A segunda é antropocêntrica, pois coloca o homem fora e acima da natureza, e a primeira não separa o homem do meio ambiente. Para ele, na sua essência, uma consciência ecológica profunda é uma consciência espiritual, pois, "quando o conceito do espírito humano é entendido como o modo de consciência no qual o indivíduo se sente conectado ao cosmo como um todo, fica claro que a consciência ecológica é espiritual em sua essência mais profunda" (CAPRA, 2005, p.20).

Dessa forma, diante das preocupações levantadas no campo da teologia, da filosofia e da ciência, que convergem num mesmo sentido, o da preservação da vida e da sua qualidade, a pesquisa tem como finalidade despertar o interesse pelos documentos da Igreja, e pelos textos-base das Campanhas da Fraternidade, que versem sobre o meio ambiente. Considerando o tamanho e a abrangência da Igreja Católica, principalmente no mundo ocidental, as suas preocupações e ações não podem ser desconsideradas. Trata-se de um aliado importante na busca de um mundo melhor para todos os seres viventes.

\section{Perspectivas da Igreja sobre o meio ambiente}

Constata a pesquisa da trajetória da história da ética que o agir está sempre relacionado com o ethos do momento. Tambémo conceito de ética está relacionado com o modo de agir de cada um. Por outro lado, o Evangelho possui os valores éticos que geram a Doutrina Social da Igreja que, por sua vez, estuda, reflete a ação da Igreja segundo esse campo.

A Igreja tem, como primeira tarefa, a evangelização dos povos, ou seja, o despertar da fé mediante o anúncio do Evangelho. Tendo em vista os problemas que afetam o meio ambiente, o propósito desta pesquisa é apresentar a colaboração da Igreja no debate, diálogo e proposições sobre o assunto que aflige a sociedade como um todo.

Por se tratar de instituição milenar e devido à sua fidelidade ao Evangelho, pela sua coerência e colaboração, quer para a formação de consciência, quer para a educação do ser humano e, principalmente, por seu trabalho de reflexão, opera com o propósito de que ocorra mudança na realidade em que vivemos. Assim, ressalta-se a importância do papel da Igreja na organização dos homens mediante a sua ação.

Há que se ressaltar que, devido à tarefa central da Igreja, que é a evangelização, a mesma quer, através da realização de campanhas e promoções, oferecer contribuições para que a sociedade possa viver uma vida melhor e mais digna.

São esses os motivos que nos levam a escolher a Igreja e a questão ambiental, para mostrar, através dos documentos que compõem o corpo da sua Doutrina Social, a sua contribuição no debate sobre a crise ecológica como um problema ético. Em nosso país ela se faz presente na Campanha da Fraternidade, que 
propõe uma reflexão para despertar a consciência dos homens e colaborar na sua educação referente ao tema.

Nesse aspecto, a apresentação da Campanha da Fraternidade quer ser, antes de tudo, uma importante ação evangelizadora que ressalte a beleza da solidariedade, com a sugestão de gestos concretos uma ortopráxis - bem como educar para um novo agir.

\section{A ecologia no Concílio Vaticano II, nos} pronunciamentos dos papas e pós-Concílio

Embora a ecologia não fosse uma preocupação por parte dos participantes do Concílio, pois a mesma não constava ainda da pauta de discussões da sociedade, mesmo assim, na Gaudium et Spes (1965), alguns acenos indiretos aparecem. A constituição fala das mudanças profundas e rápidas que se desenvolvem continuamente no universo inteiro, provocadas pela inteligência e atividades humanas (GS 4).

Os parágrafos 12 e 34 da referida constituição nos lembram de que o ser humano foi criado à imagem e semelhança de Deus, constituído "senhor de todas as coisas terrenas, para que as dominasse e usasse, glorificando a Deus" (cf. Gn 1,26; Sb 2,23; Eclo 17, 3-10), e que Deus fez boas todas as coisas (Gn 1,31). Mas a atividade humana foi corrompida pelo pecado (GS 37).

\section{Concílio Vaticano II: Gaudium et Spes n. ${ }^{\text {os } 37,}$ 64, 69 e 70}

O Concílio procurou preservar o princípio do destino universal dos bens, que sempre estará presente em documentos sucessivos da Igreja: "Deus destinou a terra, com tudo que nela contém, para o uso de todos os homens e povos, de tal modo que os bens criados devem bastar a todos, com equidade, sob as regras da justiça, inseparável da caridade" (GS 69). Assim, os ricos têm obrigação de socorrer os pobres não apenas com o que lhes é supérfluo. As decisões econômicas devem atender às necessidades individuais e coletivas da geração presente. Mas é preciso "prever o futuro, estabelecendo justo equilíbrio entre as necessidades atuais de consumo, individual e coletivo, e as exigências de inversão de bens para as gerações futuras" (GS 70). Dessa forma, trata do tema que será mais tarde discutido, "desenvolvimento sustentável".

Papa Paulo VI e suas preocupações ecológicas A Carta Encíclica Populorum Progressio, do Papa Paulo VI (1967), fala-nos do desafio do desenvolvimento e aborda a natureza da pobreza e dos conflitos por ela gerados. O documento articula o papel da Igreja no processo de desenvolvimento e esboça a visão cristã do mesmo. Ele conclama para uma ação urgente que respeite o destino universal das coisas criadas e defende a necessidade de um planejamento universal e de ajuda para o desenvolvimento. Paulo VI insiste na equidade que deve existir nas relações de comércio e na caridade universal. Por fim, conclui afirmando que o desenvolvimento é o novo nome da paz e exorta os cristãos a lutar pela justiça.

Em sua encíclica, Paulo VI amplia o alcance da abordagem do Papa Leão XIII, que trata da luta entre classes ricas e pobres, para tratar especificamente do conflito entre nações ricas e pobres. A Populorum Progressio é a primeira encíclica dedicada inteiramente ao tema do desenvolvimento. Aencíclica nos aponta as causas econômicas da guerra e recomenda a justiça econômica como base da paz.

Paulo VI faz uma crítica incisiva aos princípios básicos do capitalismo. Por outro lado, coloca um dos princípios que ainda hoje podem nortear o comportamento humano diante do meio ambiente: "Herdeiros das gerações passadas e beneficiários do trabalho dos nossos contemporâneos, temos obrigações para com todos, e não podemos desinteressar-nos dos que virão depois de nós" (n. $\left.{ }^{\circ} 17\right)$.

A partir dos anos 1970, a Igreja acompanha mais de perto a questão ecológica. Ressaltamos trechos da mensagem de Paulo VI ao secretário-geral da Conferência Internacional das Nações Unidas, sobre o Ambiente, de Estocolmo, em 1972, que reforçam as preocupações da comunidade mundial reunida na conferência: "Hoje, de fato, há maior consciência de que o homem e o ambiente em que ele vive são mais do que nunca inseparáveis". Continuando, o Papa 
insiste na necessidade de respeitar os limites da natureza: $\mathrm{O}$ homem deve "respeitar as leis que regulam o impulso vital e a capacidade de regeneração da natureza; ambos, portanto, são solidários e compartilham um futuro temporal comum". Nesse sentido, Paulo VI (1972) pergunta-se:

"Mas como se hão de ignorar os desequilíbrios provocados na biosfera, devidos à exploração desordenada das reservas físicas do planeta, até com o propósito de produzir os bens úteis, como, por exemplo, o desperdício dos recursos naturais não renováveis, a poluição do solo, da água, do ar e do espaço, com os consequentes atentados contra a vida vegetal e animal?" (PAULO VI, 1972).

Sobre a técnica que pode ser usada para diminuir os males já causados ao ambiente, o Papa frisa que "... todas as medidas técnicas serão ineficazes, se não forem acompanhadas por uma tomada de consciência da necessidade de uma transformação radical das mentalidades" (PAULO VI, 1972).

Paulo VI convida-nos a imitar o exemplo de São Francisco de Assis, como modelo para a nossa relação com a natureza. Para isso, o Papa nos afirma que: "Governar a natureza significa, para a raça humana, não destruí-la, mas aperfeiçoá-la; não transformar o mundo num caos inabitável, mas numa bonita casa, ordenada no respeito por todas as coisas" (PAULO VI, 1972). Aquestão do ambiente natural faz parte do bem comum, ou seja, é um patrimônio da humanidade.

Em virtude do XXV aniversário da FAO (Organização Mundial para a Agricultura e Alimentação, 22/11/1970), o Papa Paulo VI, em seu discurso, tece um elogio aos grandes esforços que a Organização tem realizado no aproveitamento das terras, águas, florestas e oceanos que resultaram em maior produtividade das culturas e, principalmente, a melhoria da fertilidade do solo com o uso racional da irrigação (GARMUS, 2007). Mas, para além do elogio, Paulo VI adverte que:
"O ritmo acelerado, a realização concreta dessas possibilidades técnicas não se verifica sem causar nocivas repercussões no equilíbrio do nosso ambiente natural, e a deterioração progressiva daquilo que convencionalmente se chama 'meio ambiente', sob o efeito dos contragolpes da civilização industrial, corre o risco de acabar numa verdadeira catástrofe ecológica" (PAULO VI, 1972).

Em comemoração aos 80 anos da publicação da Encíclica Rerum Novarum, o Papa Paulo VI escreve, em 14 de maio de 1971, a Carta Apostólica Octogésima Adveniens, na qual volta a chamar a atenção para as consequências provocadas pela atividade do ser humano. A advertência consta no parágrafo 21, que versa sobre o tema específico do meio ambiente, que transcrevemos:

"À medida que o horizonte do homem assim se modifica, a partir das imagens que se selecionam para ele, outra transformação começa a fazer-se sentir, consequência tão dramática quanto inesperada da atividade humana. De um momento para outro, o homem toma consciência dela: por motivo da exploração inconsiderada da natureza, começa a correr o risco de destruí-la e de vir a ser, também ele, vítima dessa degradação. Não só já o ambiente material se torna uma ameaça permanente, poluições e lixo, novas doenças, poder destruidor absoluto; é mesmo o quadro humano que o homem não consegue dominar, criando assim, para o dia de amanhã, um ambiente global, que poderá tornar-se lhe insuportável. Problema social de envergadura, este, que diz respeito à inteira família humana" (PAULO VI, 1971).

No período de 19 a 30 de agosto de 1974, em Bucareste, a ONU realizou a Conferência Mundial da População que contou com a presença da delegação da Santa Sé, que falou em nome do Papa Paulo VI. A 
intervenção da delegação afirma que há possibilidade de criar recursos alimentares e energéticos para uma população muito maior, mas os países ricos consomem $87 \%$ da energia disponível; portanto, os mesmos deveriam rever seu estilo de vida consumista, que prejudica meio ambiente.

No dia 29 de fevereiro de 1976 comemorou-se o Dia Mundial do "Habitat" Humano. O Vaticano apresentou, à Organização das Nações Unidas e também aos Bispos do mundo inteiro, o texto como sua participação na Conferência da ONU sobre o "habitat" humano. A Conferência foi realizada em Vancouver, no Canadá, de 31 de maio a 11 de junho de 1976.

Em sua Mensagem à Conferência da Organização das Nações Unidas, sobre o Meio Ambiente em Vancouver (24/05/1976), no Canadá, cujo tema era "Uma política do 'habitat' humano para o desenvolvimento integral do homem", Paulo VI renova a sua esperança no sentido de que o evento possa trazer contribuições importantes para o habitat humano e a preocupação com o desenvolvimento integral do homem.

\section{A ecologia nos pronunciamentos do Papa João Paulo II}

O Papa João Paulo II (1979), no início de seu pontificado, publica a Carta Encíclica Redemptor Hominis - Redentor do Homem -, onde demonstra sua preocupação ecológica: "As políticas que regem a economia mundial submetem o homem a tensões por ele mesmo criadas, dilapidando, num ritmo acelerado, os recursos materiais e energéticos, comprometendo o ambiente geofísico".

O Papa afirma que a exploração da terra e do planeta para fins industriais e militares, e a técnica não controlada, "trazem muitas vezes consigo a ameaça para o ambiente natural do homem, alienam-no nas suas relações com a natureza e o separam da mesma natureza" (JOÃO PAULO II, 1979).

Em 30 de dezembro de 1987, João Paulo II publica a sua Carta Encíclica Sollicitudo Rei Socialis Solicitude Social da Igreja, que trata, em diferentes momentos, a questão da ecologia. A encíclica comemora os 20 anos da Populorum Progressio de Paulo VI, que atualiza o ensino da Igreja sobre o desenvolvimento internacional. O documento reflete a gravidade da situação econômica mundial no fim dos anos 80 , com a dívida, o desemprego e a recessão afetando seriamente a vida de milhões de humanos, não só nos países subdesenvolvidos, mas também nos países ricos.

De início, a carta fala da necessidade de respeitar a natureza e seus ritmos, conforme o parágrafo 26 , que se resume ao que chamamos de preocupação ecológica. Depois, no parágrafo 29, João Paulo II insiste nos limites do domínio humano. No parágrafo 34, o Papa nos fala sobre o respeito com as diversas categorias de seres vivos ou inanimados - animais, plantas, elementos naturais e, se refere ao desenvolvimento, mas que se atente à renovação dos recursos naturais, ao perigo diante das limitações dos recursos naturais, sendo que alguns não são renováveis, e também ao domínio absoluto sobre a utilização de alguns recursos tidos como inesgotáveis.

Na sua Carta Encíclica Laborem Exercens (1981), João Paulo II afirma que a Igreja não é contra o progresso científico técnico: "a técnica é, indubitavelmente, uma aliada do homem. Ela facilitalhe o trabalho, aperfeiçoa-o e o multiplica". O que não deve ocorrer é que, em nome do progresso técnico, haja um domínio sobre o homem e destruição da natureza.

Em 28 de janeiro de 1982, na Lineamenta para o Sínodo dos Bispos de 1983, Jozef Tomko, secretáriogeral do Sínodo dos Bispos, afirma que, "no fundo, o homem aspira à reconciliação consigo mesmo, com os outros e com a natureza, a qual se consegue com a fundamental e simultânea reconciliação com Deus através da conversão e da penitência".

A Exortação pós sinodal Christifidelis Laici sobre Vocação e Missão dos Leigos na Igreja e no Mundo, do Papa João Paulo II, publicada em 30 de dezembro de 1988, recorda que recebemos de Deus os dons da natureza e que devem ser cuidados, usados com respeito e amor e passados em melhores 
condições para as gerações futuras

No ano de 1990, na Mensagem para a 23. ${ }^{a}$ Jornada Mundial pela Paz, João Paulo II faz novamente a relação da paz com Deus Criador e a paz com a criação. No início da mensagem, o Papa faz uma contextualização do momento, ou seja, existe uma crescente consciência de que a paz mundial está ameaçada, quer diante da corrida armamentista, dos conflitos regionais, das injustiças existentes entre povos e nações, quer pela falta do devido respeito pela natureza.

Depois da mensagem, apresenta a fundamentação bíblica de várias passagens da Sagrada Escritura que iluminam a relação entre o agir humano e a criação. A mensagem aborda outras questões: a crise ecológica como problema moral, a busca de uma solução, a urgência de uma nova solidariedade e a responsabilidade de todos na questão ecológica. Por último, dá-nos como exemplo de agir humano em relação à ecologia, São Francisco de Assis, que em 1979 foi declarado patrono celeste dos ecólogos.

Na comemoração do centenário da Encíclica Rerum Novarum, de Leão XIII, João Paulo II escreve a Carta Encíclica Centesimus Annus, publicada em 1. ${ }^{\circ}$ de maio de 1991, onde alerta para o fenômeno do consumismo, que é prejudicial à saúde física e espiritual e fala da degradação do ambiente natural.

Na Carta Encíclica Evangelium Vitae, de 23 de março de 1995, João Paulo II faz um apelo: "O homem é convidado a uma verdadeira conversão a fim de reconhecer a beleza da criação e preservar o 'bem comum' de toda a humanidade. Ele é convidado a libertar-se da escravidão do consumo e da corrida para ter 'sempre mais'. Deve reencontrar o sentido da gratuidade de mudar o próprio modo de ver, a fim de aprender a considerar a criação como dom de Deus, como único criador".

Em 2003, João Paulo II, na Exortação Apostólica Pós Sinodal conclama a todos, insistentemente ao respeito pelo ambiente e à salvaguarda da criação, reinterpretando, de forma dramática, o texto da Carta de São Paulo aos Romanos 8,22: "O gemido das criaturas". Também conclama os bispos a assumirem, na pregação, a tarefa de uma conversão ecológica.

\section{Preocupações ecológicas de Bento XVI}

Para comemorar a Populorum Progressio, de Paulo VI (1967), Bento XVI publica em 29 de junho de 2009, a Carta Encíclica Caritas in Veritate - Sobre o desenvolvimento humano integral na caridade e na verdade para propor a volta da ética. Bento XVI, inspirado pela fé em um Deus que é amor e verdade, quer resgatar o essencial: humanismo, justiça, cuidado, gratuidade, solidariedade.

A encíclica nos apresenta indicações e estratégias para enfrentar a hegemonia do mercado pelo poder do capital; e também, diante do surgimento do retorno da política, a democratização do poder por meio da participação cidadã; aponta uma opção firme em defesa dos pobres e da criação, e uma economia aberta ao paradigma da gratuidade (GASDA, 2011).

O Papa, na sua encíclica, estabelece como objetivo o dever de solidariedade que deve estar sempre presente: no desenvolvimento econômico, na sociedade civil, nos direitos e deveres das pessoas, no meio ambiente, na colaboração da família humana e na evolução da técnica. Sobre o desenvolvimento humano integral na caridade e na verdade, do Papa Bento XVI $(2009,96-97)$ ensina-nos que:

"A Igreja sente o seu peso de responsabilidade pela criação e deve fazer valer esta responsabilidade também em público. Ao fazê-lo, não tem apenas de defender a terra, a água e o ar como dons da criação que pertencem a todos, mas deve sobretudo proteger o homem da destruição de si mesmo. Requer-se uma espécie de ecologia do homem, entendida no justo sentido. De fato, a degradação da natureza está estreitamente ligada à cultura que molda a convivência humana: quando a "ecologia humana" é respeitada dentro da sociedade, beneficia também a ecologia ambiental. Tal como as virtudes humanas são intercomunicantes, de modo que o 
enfraquecimento de uma põe em risco também as outras, assim também o sistema ecológico se rege sobre o respeito de um projeto que se refere tanto à sã convivência em sociedade como ao bom relacionamento com a natureza" (BENTO XVI,2009, 96-97).

Ainda, a mesma encíclica nos alerta para o direito primário à vida: "[...] é necessária a maturação duma consciência solidária que considere a alimentação e o acesso à água como direitos universais de todos os seres humanos, sem distinções nem discriminações" (BENTO XVI, 2009, 44). Em relação à economia solidária, o documento assim se expressa: "é preciso dar forma e organização àquelas iniciativas econômicas que, embora sem negar o lucro, pretendamir mais além da lógica da troca de equivalentes e do lucro como fim em si mesmo" (BENTO XVI, 2009, 67).

Sobre a natureza, como expressão de um desígnio de amor e da verdade, o referido documento nos afirma que: "A natureza está à nossa disposição, não como 'um monte de lixo espalhado ao acaso', mas como um dom do Criador que traçou os seus ordenamentos intrínsecos, dos quais o homem há de tirar as devidas orientações para a 'guardar e cultivar"' (BENTO XVI, 2009, 90-91).

\section{A ecologia nos documentos das Conferências Gerais do CELAM}

A primeira Conferência Geral do Episcopado Latino-Americano (CELAM) foi no Rio de Janeiro, em 1955. Já a II Conferência Geral do Episcopado Latino-Americano foi realizada em Medellín (1968) e teve grande importância para a América Latina, pelas suas reflexões e decisões que orientaram o trabalho tendo como tema: "A Igreja na atual transformação da América Latina, à luz do Concílio Vaticano II". Sobre a questão da ecologia, o documento da Conferência assim se refere de forma doutrinária:

"O mesmo Deus, que cria o homem à sua imagem e semelhança, cria a terra e tudo o que nela existe para uso de todos os homens e de todos os povos, de modo que os bens criados possam bastar a todos de maneira mais justa (GS 39), e lhe dá poder para que solidariamente transforme e aperfeiçoe o mundo (Gn 1,26)" (MEDELLÍN, 1968, 46).

Garmus (2007) "relata ainda a percepção de que Deus deixou os bens da Terra para todos os seres vivos e não apenas para todos os seres humanos".

As conclusões da III Conferência Geral do Episcopado Latino-Americano, que se realizou em Puebla (1979), orientam-se para a recepção dos pontos básicos da evangelização na América Latina que foram propostos em Medellín. Nesse documento não se faz a ligação com o Vaticano II, mas com o contexto do continente, haja vista o título do mesmo: "A Evangelização no presente e no futuro da América Latina" (1979).

O documento refere-se, várias vezes, à questão ecológica. Na primeira parte, no capítulo IV, aborda as tendências atuais e evangelização no futuro; e ao se referir à sociedade, o parágrafo 139 ressalta a necessidade de mudança das tendências atuais; caso contrário, "continuará a deteriorar-se a relação do homem com a natureza pela exploração irracional de seus recursos". Também o mesmo parágrafo nos afirma que, se não houver mudança, corre-se o risco da "contaminação do ambiente, com o aumento de graves prejuízos para o homem e para o equilíbrio ecológico" (PUEBLA, 1979, 171).

A segunda parte do documento, capítulo I, item 2o, parágrafo 327, afirma que: "[...] o domínio, o uso e a transformação dos bens da terra, dos bens da cultura, da ciência e da técnica se vão realizando em um justo e fraterno domínio do homem sobre o mundo, tendose em conta o respeito da ecologia" (PUEBLA, 1979, 170). Já o parágrafo 386 (p. 184), que integra o capítulo II da segunda parte do documento, no item 2o, orientanos e solicita que haja o "cultivo da relação com a natureza".

Ao se reportar à libertação do ídolo da riqueza, o documento, na sua segunda parte, capítulo II, item 4o, parágrafo 496 (PUEBLA, 1979, 214-215), denuncia 
de forma profética os efeitos desastrosos da industrialização, da urbanização e do consumismo:

\section{"[...] importa tomar consciência dos efeitos} devastadores de uma industrialização descontrolada e de uma urbanização que vai tomando proporções alarmantes. Os esgotamentos dos recursos naturais $e$ a contribuição do ambiente constituirão um problema dramático".

"Afirmamos uma vez mais a necessidade de uma profunda revisão da tendência consumista das nações mais desenvolvidas; cumpre levar em consideração as necessidades elementares dos povos pobres que formam a maior parte do mundo" (PUEBLA, 1979, 214-215).

O texto, na sua quarta parte, capítulo III, ao falar sobre a ação da Igreja junto aos construtores da sociedade pluralista na América Latina, apresenta, em suas linhas de ação pastoral, objetivos, opções e estratégias, como princípio norteador, no parágrafo 1236: "Preservar os recursos naturais criados por Deus para todos os homens, a fim de transmiti-los como herança às gerações vindouras" (PUEBLA, 1979, 374).

No ano de 1992, acontece em Santo Domingo a IV Conferência Geral do Episcopado LatinoAmericano, que teve como tema: Nova evangelização, promoção humana e cultura cristã. Entre os desafios que a Igreja do continente latinoamericano e caribenho deve enfrentar, e que constam dos parágrafos 168, 169 e 172 do documento, estão a defesa da vida, a ecologia e a terra, que é considerada dom de Deus e lugar sagrado e que deve ser distribuída com justiça.

No capítulo II, item 2.2, o documento versa sobre os novos sinais dos tempos no campo da promoção humana, e o parágrafo 169 salienta a causa da sacralidade da natureza, a saber:

"A criação é obra da Palavra do Senhor e da presença do Espírito, que desde o início, pairava sobre tudo o que foi criado (Gn 1-2). Esta foi a primeira aliança de Deus conosco. Quando o ser humano, chamado a entrar nesta aliança de amor, se nega, o pecado do homem afeta sua relação com Deus e com toda a criação" (SANTO DOMINGO, 1992, 155).

No parágrafo acima referido, Santo Domingo (1992) menciona os desafios a serem enfrentados, como a realização da Conferência das Nações Unidas e o Desenvolvimento no Rio de Janeiro, que pôs em relevo mundial a crise ecológica. Destacou-se o problema das grandes cidades; no campo, a perda das terras por parte de populações indígenas; o desmatamento e as queimadas, sobretudo na Amazônia.

É interessante observar que o documento de Santo Domingo, ao lado dos desafios, propõe linhas pastorais destinadas ao agir do cristão, as quais integra a sociedade, a fim de provocar-lhe a responsabilidade em relação às escolhas e opções por modelos de desenvolvimento que causaram os atuais desastres ambientais e sociais. Entre essas linhas podemos citar: reeducação das crianças e jovens diante do valor da vida, a interdependência dos diversos ecossistemas, o cultivo de uma espiritualidade que recupere o sentido da presença de Deus na criação, dar valor à nova plataforma de diálogo que a crise ecológica criou, e questionar a riqueza e o desperdício.

O texto confirma a crença dos povos de que a terra é o primeiro sinal da Aliança de Deus com o homem. Através da revelação bíblica, aprendemos que Deus criou o homem e o colocou no centro do jardim do Éden com a finalidade de cuidar, cultivar e fazer uso do mesmo, estabelecendo alguns limites (Gn 2,17) "que recordariam sempre ao homem que 'Deus é o Senhor e criador, e dele é a terra e tudo que nela existe' e que ele a pode usar, não como dono absoluto, mas como administrador".

A V Conferência Geral do Episcopado LatinoAmericano e do Caribe aconteceu em 2007, em Aparecida, e enfoca a questão ecológica em diferentes momentos e sob diversos olhares. No seu discurso 
inaugural, Bento XVI, ao olhar para a situação econômica, propõe que haja um desenvolvimento global e solidário, que se considere com preferência as outras dimensões humanas, "pondo tudo ao serviço da pessoa humana, criada à imagem e semelhança de Deus" (APARECIDA, 2007, 270).

O parágrafo 66 do documento de Aparecida denuncia que frequentemente se subordina a preservação da natureza ao desenvolvimento econômico e, com isso, gera danos à biodiversidade, como o esgotamento das reservas de água e outros recursos naturais, a contaminação do ar e a mudança climática. Chama a atenção para o estudo das possibilidades e eventuais problemas da produção do agrocombustível, a fim de que prevaleça o valor da pessoa humana e de suas necessidades de sobrevivência.

O documento de Aparecida, nos parágrafos 8397, refere-se à biodiversidade, à ecologia, à Amazônia e à Antártida. O parágrafo 83 menciona que o continente possui uma das maiores biodiversidades do planeta, bem como possui uma rica sociodiversidade, que é representada por seus povos e culturas. Eles são portadores de um grande acervo de conhecimentos tradicionais sobre a utilização dos recursos naturais, e o valor medicinal das plantas que integram a base de sua economia. Porém, tudo isso é objeto de apropriação ilícita, gerando patentes a indústrias farmacêuticas e de biogenética. Nesse sentido, o parágrafo 84 relata que decisões são tomadas sobre a riqueza da biodiversidade e da natureza sem consulta às populações tradicionais.

O documento, no parágrafo 126 , também ensinanos que é importante visar ao bem da pessoa humana, recordando que "o Senhor entregou o mundo para todos, para as gerações presentes e futuras". Também alerta que em virtude dos recursos serem cada vez mais limitados, é necessária a exigência da solidariedade com as gerações futuras.

Sobre apoiar a participação da sociedade civil, o documento, no parágrafo 406, fala-nos que: "[...] são muito importantes os espaços de participação da sociedade civil para a vigência da democracia, uma verdadeira economia solidária e um desenvolvimento integral, solidário e sustentável". Já o parágrafo 473, afirma-nos a necessidade de um desenvolvimento para o continente daAmérica Latina, mas para isso é preciso impedir a devastação das florestas e a contaminação da água.

Ao se referir sobre o cuidado com o meio ambiente, o documento, no seu parágrafo 470, convida-nos a "[...] dar graças pelo dom da criação, reflexo da sabedoria e beleza do Logos criador". Também convoca, a cada um, "a viver em comunhão com Ele, e em comunhão entre si e com toda a criação". Além disso, o Senhor da Vida "recomendou ao ser humano sua obra criadora para que a cultivasse e a guardasse (Gn 2,15)". Assim, os parágrafos 470-473 anunciam ações a favor do cuidado com o meio ambiente, e denunciam ações "que o atual modelo econômico, que privilegia o desmedido afã pela riqueza, acima da vida das pessoas e dos povos e do respeito racional pela natureza". Além disso, o documento de Aparecida oferece algumas propostas e orientações, presentes no parágrafo 474, a saber:

a) Evangelizar nossos povos para que descubra o dom da criação, sabendo contemplá-la e cuidar dela como casa de todos os seres vivos e matriz da vida do planeta, a fim de exercitar responsavelmente o senhorio humano sobre a terra e sobre os recursos para que possam render todos os seus frutos em uma destinação universal, educando para um estilo de vida de sobriedade e austeridade solidárias;

b) Aprofundar a presença pastoral nas populações mais frágeis e ameaçadas pelo desenvolvimento predatório e apoiá-las em seus esforços para conseguir uma equitativa distribuição da terra, da água e dos espaços urbanos;

c) Procurar um modelo de desenvolvimento alternativo, integral e solidário, baseado em uma ética que inclua a responsabilidade por uma autêntica ecologia natural e humana, que se fundamente no evangelho da justiça, da solidariedade e do destino universal dos bens, e que supere a lógica utilitarista e individualista, que não submete os poderes econômicos e tecnológicos a critérios éticos. Portanto, estimular 
nossos homens do campo a se organizarem de tal maneira que possam conseguir sua justa reivindicação;

d) Empenhar nossos esforços na promulgação de políticas públicas e participações cidadãs que garantam a proteção, conservação e restauração da natureza;

e) Determinar medidas de monitoramento e de controle social sobre a aplicação dos padrões ambientais internacionais nos países.

No que diz respeito ainda a propostas e orientações, o parágrafo 475 ressalta a importância de conscientização sobre a Amazônia, propondo uma "pastoral de conjunto com prioridades diferenciadas para criar um modelo de desenvolvimento que privilegie os pobres e sirva ao bem comum".

\section{A CNBB e a questão ambiental}

A Conferência Nacional dos Bispos do Brasil (CNBB) é uma instituição permanente da Igreja Católica no País, que congrega os bispos e que:

"[...] a exemplo dos Apóstolos, conjuntamente e nos limites do direito, eles exercem algumas funções pastorais em favor de seus fiéis e procuram dinamizar a própria missão evangelizadora, para melhor promover a vida eclesial, responder mais eficazmente aos desafios contemporâneos, por formas de apostolado adequadas às circunstâncias, $e$ realizar evangelicamente seu serviço de amor, na edificação de uma sociedade justa, fraterna e solidária, a caminho do Reino definitivo" (www.cnbb.org.br).

A realização da assembleia-geral da $\mathrm{CNBB}$, que acontece a cada ano, tem como uma de suas finalidades oferecer uma reflexão em forma de documento, referente a problemas e questões que afligem o cotidiano da vida do povo brasileiro. Em sintonia com o estudo da ética, da doutrina social da Igreja e meio ambiente pesquisamos os seguintes documentos: Igreja e problemas da Terra (1980); Solo urbano e ação pastoral (1982); Ética: Pessoa e Sociedade (1993); Por uma reforma do Estado com participação democrática (2010); e Diretrizes Gerais da Ação Evangelizadora da Igreja no Brasil 2011-2015.

Tendo em vista a importância da questão da terra em nosso país, a CNBB debateu e refletiu, na sua $18 .{ }^{a}$ assembleia geral, em 14 de fevereiro de 1980, e elaborou do documento, intitulado: A Igreja $e$ Problemas da Terra. O objetivo do documento é abordar a problemática da posse da terra no Brasil (CNBB, 1980, 01). Não se trata de um estudo sobre agricultura, mas uma reflexão sobre a questão social da propriedade fundiária. $\mathrm{O}$ documento aborda a realidade referindo-se: à concentração da propriedade da terra; ao modelo político a serviço da grande empresa; à questão das terras dos povos indígenas; às migrações e à violência no campo.

A fundamentação doutrinal do referido documento tem como base a Doutrina Social da Igreja, que muitas vezes já tratou do problema da propriedade e, mais explicitamente, a propriedade da terra. A Doutrina Social da Igreja não foi somente formulada como resposta aos desafios enfrentados pela sociedade, mas tem o seu fundamento na longa tradição da Igreja, suas raízes na Sagrada Escritura, na mensagem de Jesus, e no pensamento dos Santos Padres e Doutores da Igreja (CNBB, 1980, 08).

\section{Estudos realizados pela CNBB sobre Meio Ambiente}

No ano de 1992, por ocasião da realização da Conferência das Nações Unidas sobre Meio Ambiente e Desenvolvimento (CNUMAD), no Rio de Janeiro, a Igreja do Brasil, por meio da CNBB promoveu, entre 18 e 21 de maio, em Brasília, o Seminário sobre Ecologia e Desenvolvimento (CNBB, 1992). O seminário aconteceu como eco da reflexão da Campanha da Fraternidade de 1979, e tendo em vista a realização da Conferência das Nações Unidas sobre o Meio Ambiente. O resultado do seminário foi publicado pela CNBB - Setor Pastoral Social - sob o título A Igreja e a questão ecológica-leitura éticoteológica a partir da análise crítica do desenvolvimento.

O documento está dividido em três partes. Aquestão 
sobre a crise do modelo de desenvolvimento, que integra a primeira parte do documento, mostra uma abordagem crítica do tema desenvolvimento, que inicia com o advento da modernidade, passando por muitas experiências no decorrer do tempo; relata também a relação do homem civilizado com o ambiente; também critica o neoliberalismo, entendendo-o como uma imposição de um paradigma que tem como centro o mercado como regulador das relações humanas.

A segunda parte começa com aspectos históricos sobre a questão do desenvolvimento sustentável que se inicia na década de 1970, com a formação do Clube de Roma. No decorrer da fala sobre os aspectos históricos, é trabalhado o conceito de desenvolvimento sustentável que, por sua vez, despertou o surgimento de propostas "que apontam para novos mecanismos de mercado, como solução para condicionar a produção à capacidade de suporte dos recursos naturais" (CNBB, 1992, 28). O tema "desenvolvimento sustentável e democracia" mostra, através de experiências práticas de lutas populares, que é possível "a construção de um novo "ethos" que oriente a busca de projetos de sociedade e a prática social e ambiental cotidiana" (CNBB, 1992, 33).

Já a terceira parte aborda a responsabilidade pela criação de Deus; está dividida em cinco subitens, a saber: 1) autocrítica das tradições judaico-cristãs; 2) sujeitar ou dominar? Guardar e cultivar! Uma releitura; 3) a presença de Deus na criação; 4) por uma ética centrada na vida; 5) e exigências de uma conversão radical proporcionando uma reflexão com o intuito de despertar a consciência do ser humano sobre as necessidades urgentes em querer salvar a criação.

A conclusão do documento aprofunda as reflexões iniciadas pela Campanha 1979, bem como chama a atenção da ação humana sobre a natureza, tornandose responsável pela sua preservação e destruição. Assim, o documento chama a atenção de todos: "é uma convocação para as urgentes mudanças que se fazem necessárias, exigindo a conversão das pessoas e das estruturas sociais". Na conclusão do documento é enfatizado que: "a elaboração de propostas de desenvolvimento deve estar subordinada a valores éticos, que garantam os direitos de toda a humanidade e o respeito à criação" (CNBB, 1992).

\section{A CNBB e as Campanhas da Fraternidade O itinerário histórico da Campanha da Fraternidade}

Ao longo de 46 anos, desde o início da primeira Campanha, os temas podem ser divididos em três fases. A primeira fase caracteriza-se como a busca da renovação interna da Igreja sob dois aspectos: a Renovação da Igreja, campanhas de 1964 e 1965; e a Renovação do Cristão, entre 1966 e 1972. Prates $(2007,56)$ afirma que "esta primeira fase composta por nove $\mathrm{CFs}$, tem como fio condutor a busca de uma experiência eclesial capaz de renovar a estrutura ou configuração interna da Igreja".

As Campanhas da Fraternidade de 1964 e 1965 abordam a necessidade de a Igreja "voltar-se para si mesma no intuito de implementar a renovação no horizonte da Lumen Gentium. Elas acabam se constituindo numa primeira etapa dentro desta primeira fase" (PRATES, 2007, 56). Essa etapa passa necessariamente pela renovação interior proposta pelo Concílio Vaticano II.

A segunda fase pode ser caracterizada pela preocupação da Igreja com a realidade social do povo, denunciando o pecado social e promovendo a justiça (Vaticano II, Medellín e Puebla). Corresponde às campanhas ocorridas desde 1973 até 1984. Nessa fase, que engloba 12 Campanhas da Fraternidade, Prates fala-nos que:

"[...] há um desdobramento eclesial-
eclesiológico no sentido de a Igreja adotar
uma postura diante da sociedade brasileira
sob a inspiração da Gaudium et spes aplicada
à sua realidade à luz das afirmações
teológicas de Medellín. O tema que inaugura
esta nova fase é articulado na linha da
relação entre fraternidade e libertação,
proporcionando uma reflexão em torno da
fraternidade-libertadora, binômio que,
amiúde, temos utilizado ao longo deste


trabalho. A complexidade da realidade social brasileira, destarte, é compreendida e interpretada por intermédio do referido binômio, o qual passa a ser chave hermenêutica que conscientiza a fé e na mesma fé sensibiliza o coração do cristão para a busca da transformação social" (PRATES, 2007, 58).

Finalmente, na terceira fase, a Igreja volta-se para situações existenciais do povo brasileiro, correspondendo às campanhas a partir de 1985 até a mais recente, ocorrida em 2011. Ao voltar a sua ação pastoral para situações existenciais concretas da vida do povo, percebemos que a Igreja quer desempenhar um papel de formação da consciência diante da realidade brasileira. Prates recorda-nos que:

"Esta fase caracteriza-se por colocar em evidência, sob a óptica da fraternidadelibertadora, diversas situações de flagelo sócios existenciais que assolam a vida do povo. Tais situações descaracterizam o sentido mais genuíno da fraternidade como elemento sócio humanizador da sociedade" (PRATES, 2007, 63).

Portanto, a partir de 1973, a Igreja no Brasil tem proposto temas para reflexão e conversão, relativos às várias situações sociais e existenciais do povo, que requerem mais fraternidade, como constam na apresentação de cada Campanha da Fraternidade.

\section{Enfoque na questão ambiental na Campanha da Fraternidade}

A escolha do enfoque do meio ambiente prende-se ao fato do estudo e da situação ética atual em que se encontra o mesmo. Por outro lado, a contribuição da Igreja Católica, através da sua Doutrina Social, quer, como integrante da sua missão evangelizadora e parte da sociedade, despertar para a consciência sobre o cuidado, a preservação e a responsabilidade com o meio ambiente.
Embora a Igreja Católica no século XIX já realizasse um diálogo com o mundo através de seus documentos, foi a partir do Concílio Vaticano II que oficializou e passou a intensificar esse diálogo com a sociedade. O diálogo se manifesta com o intuito de expor a sua posição e orientação sobre problemas que afetam a existência e a continuidade da humanidade.

Outro detalhe importante é que os textos-base das Campanhas da Fraternidade especificamente assumem o debate, a reflexão sobre os problemas existenciais do ser humano que acabam interferindo na mudança do agir do mesmo. Durante a caminhada da Campanha da Fraternidade, já foram abordadas várias situações importantes para a vida do ser humano, contando, inclusive, com a colaboração de outras Igrejas cristãs, como gesto concreto do diálogo ecumênico, nos anos, 1979, 2004, 2007 e 2011.

Em 1979, acontece a Campanha da Fraternidade Por um mundo mais humano - Preserve o que é de todos - que é a primeira campanha voltada para as questões do meio ambiente. A mesma lançou compromissos e perspectivas de ação conforme consta do texto-base que são: a) Uma nova mentalidade; b) Uma questão de educação; c) Muitos gestos concretos, e d) Celebrações de datas significativas (CNBB, 1979).

A justificativa da escolha do tema para Campanha da Fraternidade está no fato de que "a ecologia é um tema profundamente fraterno" e "a natureza criada por Deus é destinada a todos os homens, Destruí-la e prejudicá-la é, portanto, um ato nocivo ao próximo" (CNBB, 1979, 10). O texto recorda que, nos últimos séculos, o homem passou de dominado pelas forças da natureza a dominador. O domínio do homem se dá pela industrialização e tecnologias que se transformaram em risco de destruição da natureza, tais como: destruição de florestas, provocando aluviões, enchentes e secas, ameaçando a própria espécie humana.

A campanha de 2004, com o tema: Água, Fonte de vida, aborda a fraternidade e a água. O texto-base da mesma, sob o olhar do ver, analisa a crise da água de forma ampla a partir de informações técnicas. Sob o olhar do julgar, busca recuperar as tradições religiosas locais, os aspectos bíblicos e teológicos e a 
questão das exigências éticas. Já o agir sugere várias possibilidades de ação, quanto ao ponto de vista religioso, celebrativo, educacional e social. Diante da necessidade do cuidado em preservar o bem comum, as ações sugeridas tendem a conscientizar sobre $o$ verdadeiro valor da água.

Em 2007, a campanha que teve como tema: Vidae missão neste chão, aborda a fraternidade e a Amazônia, com a finalidade de preservar a rica "sociobiodiversidade" contra todas as formas de devastação, motivadas pela ambição do lucro. Ressalta-se o consenso geral de que "a Amazônia constitui-se num fator de equilíbrio essencial para todo o planeta, e que a vida da região tem a ver com a qualidade de vida global da Terra e ainda, tem como objetivo promover a fraternidade efetiva com as populações amazônicas, bem como defender e promover a vida que se manifesta com tanta abundância na Amazônia (CNBB, 2007)".

A Campanha da Fraternidade de 2011 teve como tema: Fraternidade e a vida no planeta, e o lema: $A$ criação geme em dores de parto $(\operatorname{Rm} 8,22)$. A sua fundamentação alicerça-se no advento da industrialização; a partir de 1750, o meio ambiente começou a sofrer alterações que, cada vez mais, deixam marcas no planeta. Além da falta de preservação, outras consequências podem ser observadas: a poluição dos mananciais, a disseminação de campos eletromagnéticos, a poluição atmosférica, a contaminação por agrotóxicos, a contaminação de solos por resíduos, e a ocorrência de desastres ambientais (CNBB, 2011).

O texto-base da mesma apresenta o objetivo geral que é: Contribuir para a conscientização das comunidades cristãs e pessoas de boa vontade sobre a gravidade do aquecimento global e das mudanças climáticas, e motivá-las a participar dos debates e ações que visam enfrentar o problema e preservar as condições de vida no planeta (CNBB, 2011, p.12). Os objetivos específicos são: viabilizar meios para formar consciência ambiental, discutir e mostrar a gravidade e urgência dos problemas ambientais e trocar experiências e propor caminhos para sua superação. Foram utilizadas como estratégias: mobilizar pessoas e instituições para a construção de alternativas para a superação dos problemas ambientais, propor atitudes, comportamentos e práticas que tenhama vida como referência, denunciar situações e apontar responsabilidades em face dos problemas ambientais (CNBB, 2011, p.12).

\section{Meio ambiente: tema transversal em diferentes Campanhas}

Outras Campanhas da Fraternidade trataram, de forma indireta, o meio ambiente, a saber: a Campanha da Fraternidade realizada em 1984, com o tema: Para que todos tenham vida, aborda, brevemente, a questão nos números 25-26 do texto-base da mesma. A campanha faz um alerta: o futuro da vida, na Terra, corre perigo.

O texto-base denuncia que esses perigos são a destruição das florestas, o envenenamento da terra, dos alimentos e das águas pelo uso de inseticidas, bem como a ameaça à Amazônia. Essa campanha foi um reforço do que foi trabalhado na Campanha da Fraternidade de 1979. E a reflexão bíblica, com fundamento nos textos da Sagrada Escritura, apresenta Deus como princípio absoluto da vida: Deus quer a vida e não a morte; e Deus é o defensor da vida.

A Campanha realizada em 1985, com o tema Pão para quem tem fome, aborda a responsabilidade criadora do homem, que não a realiza de modo solitário; a campanha de 1986, com o tema Terra de Deus, Terra de Irmãos, aborda o "desafio da realidade, apelos de Deus diante da problemática da terra, e Terra e Ação Pastoral da Igreja"; a campanha de 1991, com o tema Solidários na dignidade do trabalho, elabora estudos sobre a terra; a campanha de 1993, com o tema Onde Moras? aborda a questão do solo urbano e o problema social; a campanha de 1998, com o tema A Serviço da vida e da esperança, aborda o desafio da educação e da ecologia, como eco da Campanha de 1979; a campanha de 2000 - ecumênica - com o tema Dignidade Humana e Paz, aborda a falta de terra e as condições de vida dos povos indígenas; a campanha de 2002, com o tema Por uma terra sem 
males, aborda a fraternidade e os povos indígenas.

A campanha de 2005 - ecumênica - com o tema Felizes os que promovem a paz, aborda a sensibilidade para com a ecologia; a campanha de 2008 com o tema Escolhe, pois a vida (Dt 30,19), aborda as ameaças à vida e ao meio ambiente; a campanha de 2009 com o tema A pazé fruto da justiça (Is 32,17), aborda a violência contra a natureza; e, finalmente, a campanha de 2010 - ecumênica - com o tema Vocês não podem servir a Deus e ao Dinheiro (Mt 6,24), aborda questões como a transformação da água em mercadoria, planeta terra - casa de todos, um desenvolvimento desequilibrado, a degradação do meio ambiente e, finalmente, o descanso da terra.

Os textos-base das Campanhas da Fraternidade realizadas pela Conferência Nacional dos Bispos do Brasil (CNBB), e seus organismos, procuram desempenhar a missão evangelizadora e, também, o despertar da consciência ética referente a assuntos relevantes para a vida do ser humano.

\section{Considerações finais}

A questão do meio ambiente chama a atenção mundial devido ao grau de degradação atingido e a falta de preservação que, pelas suas consequências, têm influenciado a vida no planeta. Além disso, a falta de planejamento adequado na administração dos recursos naturais acaba promovendo, cada vez mais, os interesses de ordem egoísta e desenfreada do lucro, contra os interesses da promoção de um desenvolvimento sustentável.

Diante disso, a pesquisa sobre Ética e meio ambiente: considerações sobre os textos-base das Campanhas da Fraternidade de 1979 e 2011, identificou, através do presente estudo que envolve aspectos conceituais e apontamentos da ética na história, que há uma relação, uma sintonia com os documentos da Igreja, especificamente com a ética do cuidado. Os documentos utilizados, que integram o corpo da Doutrina Social da Igreja são: as encíclicas papais, os documentos das Conferências Gerais do Episcopado Latino-Americano e Caribe, e da Conferência Nacional dos Bispos do Brasil, em especial os textos-base das Campanhas da Fraternidade de 1979 e 2011.

Como consta do corpo da pesquisa, é visível a sintonia dos mencionados documentos com a ética, com o intuito de despertar, valorizar a formação da consciência que se revela no agir ético, principalmente com a preservação do meio ambiente, que significa o cuidado com a criação, que busca também estimular o desenvolvimento e o fortalecimento do modo-de-sercuidado.

Assim sendo, a concretização do modo-de-sercuidado realiza-se em diferentes instâncias como: cuidado com o nosso único planeta; cuidado com o próprio nicho ecológico; cuidado com a sociedade sustentável; cuidado com o outro, animus e anima; cuidado com os pobres, oprimidos e excluídos; cuidado com nosso corpo na saúde e na doença; cuidado com a cura integral do ser humano; cuidado com a nossa alma - os anjos e os demônios interiores; cuidado com o nosso espírito - os grandes sonhos e Deus; e o cuidado com a grande travessia - a morte.

Outro ponto importante que percebemos é que os textos-base das Campanhas da Fraternidade são uma forma de a Igreja colaborar com a sociedade civil, respondendo às necessidades de preservação do meio ambiente. Inserem-se em um processo de diálogo com o mundo, dando sua contribuição para o melhor encaminhamento dos problemas existenciais da humanidade.

As Campanhas da Fraternidade, não sendo integrantes do poder público, agem através das propostas, indicando uma nova política pública, que venha a satisfazer as necessidades humanas, principalmente em favor da vida.

Desse modo, as Campanhas da Fraternidade, durante a sua existência, tornam-se um novo ator, ou atores que, diante da utilização do seu método "verjulgar-agir", colaboram no sentido de despertar a consciência e tornar o ser humano mais participativo no enfrentamento e na resolução de seus problemas.

Por outro lado, a realização da Campanha da Fraternidade de 1979 torna-se uma ação de vanguarda da Igreja ao propor a reflexão sobre a 
preservação do meio ambiente, trazendo o alerta para a sociedade bem antes que as ações governamentais do país. Como consequências, o texto-base apontanos para uma nova mentalidade: a ecologia chamanos a superar o egoísmo, o consumismo e a ganância de possuir sempre mais.

$\mathrm{Na}$ questão de educação, a defesa do meio ambiente passa necessariamente pela aquisição e irradiação de hábitos sadios, ou seja, o início da educação deve acontecer na família, nos momentos apropriados, e sistematizar-se na escola com a introdução de aulas de ecologia.

A realização da Campanha da Fraternidade de 2011 está inserida dentro das preocupações da humanidade que são o aquecimento global e as mudanças climáticas. Desse modo, o estudo do texto-base da mencionada Campanha procura gerar uma mudança de mentalidade nas pessoas envolvidas. A terceira parte do texto-base, que versa sobre gestos concretos, convida-nos a tomar uma posição, principalmente um comportamento, um agir voltado para a ética do cuidado diante das ressonâncias que dele ecoam.

Para o arquiteto e professor Maurício Andrés Ribeiro, o aprofundamento da consciência ambiental (uma constante preocupação da Igreja Católica a partir do Concílio Vaticano II) é necessário para a construção de caminhos para uma cultura de paz com a natureza:

"O aprofundamento da consciência e da percepção ambiental, bem como a maior sensibilização social e individual, mostra que a paz social está associada a relações amigáveis com o ambiente e que a ignorância e a autocomplacência precisam ceder lugar a padrões éticos e à ação com responsabilidade. o desenvolvimento sustentável, em sua dimensão cultural, depende de um conjunto de valores, internalizados pelo cidadão, e que orienta seu comportamento para uma relação menos agressiva. Um ser humano mais amoroso, sensivel, cuidadoso e gentil para com a Terra, para com sua espécie e com as demais espécies vivas, transcendendo aspectos rudimentares de sua animalidade $e$ valorizando suas características mais elevadas, terá maiores possibilidades de projetar e construir um ambiente saudável" (RIBEIRO, 2006, p. 63).

A construção de caminhos para uma cultura de paz com a natureza é tarefa que deve ser feita por muitas mãos. Afamília, a escola, os governos, as organizações da sociedade civil, as empresas, as igrejas etc. têm papéis a cumprir neste processo. A Igreja Católica, através das Campanhas da Fraternidade, tem feito esforços em relação aos seus muitos fiéis para divulgar informações sobre os problemas ambientais que afligem a humanidade e todos os seres viventes, com o objetivo de desenvolver consciência e responsabilidade ambiental. A clareza didática dos textos-base das Campanhas e a imensa propaganda que é feita nas paróquias em relação aos temas abordados cumprem um papel educacional relevante, são mais uma contribuição à causa do meio ambiente entre muitas outras também importantes.

Resumidamente: as Campanhas da Fraternidade com temas ambientais podem servir para educar no sentido da superação da ignorância e da autocomplacência para que elas cedam lugar a padrões éticos de comportamento e de responsabilidade para com todas as formas de vida, religando o espírito humano à natureza, ao todo.

Para concluir, afirmamos que o assunto não se esgota aqui. A pesquisa não tem a pretensão de apresentar resultados práticos, mas de propor o estudo, a reflexão, para despertar a formação de consciência por uma ética centrada na vida. Ao mesmo tempo quer trazer ao conhecimento de todos a questão ética, de modo particular, uma ética do cuidado. Ela se faz presente nos documentos que integram a Doutrina Social da Igreja, principalmente os textos-base das Campanhas da Fraternidade, que são formas de diálogo com a sociedade, manifestando sua preocupação com os problemas existenciais do ser humano. Essas manifestações da Igreja Católica corroboram a necessidade de se construir uma ética 
planetária, nos moldes propostos por Gallo em Ethos, a grande morada humana: economia, ecologia e ética:

"A necessidade de se construir uma ética para o planeta Terra é de extrema importância e sua relevância para a própria sobrevivência da humanidade é, cada vez mais, inquestionável. A morada humana não cabe mais dentro apenas dos limites estreitos do estado-nação, ela se estende por toda a Terra. Doravante, então, é necessário modelá-la para que ela consiga sustentar um novo projeto de civilização baseado na paz e no cuidado. É preciso fundar um novo ethos para permitir uma convivência nova entre os homens e destes com os demais seres. A nova ética deverá nascer da essência, da natureza mais profunda do ser humano. Ocorre que a essência do homem está muito mais no cuidado, na compaixão, do que na razão $e$ na vontade. Há que se resgatar a essência do humano. É preciso ir além da ciência" (GALLO, 2007, 117-118).

\section{REFERÊNCIAS}

\section{BENTO XVI. Carta Encíclica Caritas in}

Veritate. São Paulo: Paulinas, 2009.

BOOF, L. Ética e moral: a busca dos fundamentos. Petrópolis, RJ: Editora Vozes, 2003.

Saber cuidar: ética do humano -

compaixão pela Terra. Petrópolis, RJ: Editora Vozes, 1999.

CAPRA, F. Alfabetização ecológica: o desafio para a educação do século 21. In: TRIGUEIRO, A. (coord.). Meio ambiente no século 21: 21 especialistas falam da questão ambiental nas suas áreas de conhecimento. Campinas: Armazém do Ipê 2005.

\section{CELAM. Conclusões da Conferência de}

Medellin - 1968. São Paulo: Paulinas, 1998.

Conclusões da Conferência de Puebla.

São Paulo: Paulinas, 1979.

\section{Conclusões da IV Conferência do}

Episcopado Latino-Americano Santo Domingo.

São Paulo: Paulinas, 1992.

Documento de Aparecida. Brasília: São

Paulo: Paulinas, 2007.

CNBB. Preserve o que é de todos. Campanha da Fraternidade. São Paulo: Ed. Salesianas, 1979.

Documentos da cnbb 17. Igreja e

problemas da Terra. 1980. www.cnbb.org.br

Documentos da cnbb 23. Solo urbano e

ação pastoral. 1982. www.cnbb.org.br

Para que todos tenham vida: Campanha da Fraternidade. São Paulo: Ed. Salesianas, 1984.

Pão para quem tem fome: Campanha da Fraternidade. São Paulo: Ed. Salesianas, 1985.

Terra de Deus, Terra de irmãos:

Campanha da Fraternidade. São Paulo: Ed.

Salesianas, 1986.

Solidários na dignidade do trabalho:

Campanha da Fraternidade. São Paulo: Ed.

Salesianas, 1991.

. Setor Pastoral Social. A Igreja e a

questão ecológica. São Paulo: Paulinas, 1992.

Onde moras? Campanha da Fraternidade.

São Paulo: Ed. Salesianas, 1993.

. Documentos cnbb 28. Ética: Pessoa e 
Sociedade. 1993. www.cnbb.org.br

. A serviço da vida e da esperança:

Campanha da Fraternidade. São Paulo: Salesianas, 1998.

. Por uma terra sem males: Campanha da Fraternidade. São Paulo: Salesianas, 2002.

. Água, fonte de vida: Campanha da

Fraternidade. São Paulo: Salesianas, 2004.

. Vida e missão neste chão: Campanha da Fraternidade. São Paulo: Salesianas, 2007.

. Escolhe, pois, a vida (Dt 30,19):

Campanha da Fraternidade. São Paulo: Salesianas, 2008.

. A paz é fruto da justiça (Is 32,17):

Campanha da Fraternidade. São Paulo: Salesianas, 2009.

Documentos da cnbb 91. Por uma reforma do Estado com participação democrática. 2010. www.cnbb.org.br

. A criação geme em dores de parto $(\mathbf{R m}$

8,22): Campanha da Fraternidade. São Paulo: Salesianas, 2011.

Documentos da cnbb 94. Diretrizes

Gerais da Ação Evangelizadora da Igreja no Brasil - 2011-2015. São Paulo: Paulinas, 2011.

CONIC. Felizes os que promovem a paz:

Campanha da Fraternidade. São Paulo: Salesianas, 2005.

Vocês não podem servir a Deus e ao dinheiro (Mt 6,24). Campanha da Fraternidade. São Paulo: Salesianas, 2010.
ALLO, Z. Ethos, a grande morada humana: economia, ecologia e ética. Itu, SP: Ottoni Editora, 2007.

GARMUS, L. Ecologia nos documentos da Igreja Católica. Revista Brasileira Eclesiástica - REB. Petrópolis: Vozes, 2007.

GASDA, E. E. Trabalho e capitalismo globalAtualidade da Doutrina Social da Igreja. São Paulo: Paulinas, 2011.

JOÃO PAULO II. Carta Encíclica Redemptor

Hominis. 1979. www.vatican.va . Carta Encíclica Laborem Exercens, 1981. www.vatican.va

. Carta Encíclica Solicitudo Rei Socialis, 1987. www.vatican.va

Exortação pós sinodal Christifidelis

Laici, 1988. www.vatican.va

Mensagem para a $23^{\mathrm{a}}$ Jornada

Mundial pela Paz, 1990. www.vatican.va

. Carta Encíclica Centesimus Annus,

1991. www.vatican.va

. Carta Encíclica Evangeliun Vitae, 1995.

www.vatican.va

Exortação Apostólica pós- sinodal, 2003. www.vatican.va

JONAS, H. El principio responsabilidad.

Barcelona: Herder, 1995.

O princípio vida: fundamentos para uma biologia filosófica. Petrópolis, RJ: Vozes, 2004.

MAGALHÃES, D. (org.). A paz como caminho. 
Rio de janeiro: Qualitymark, 2006.

NAHRA, J. J. A. Ética e meio ambiente: considerações sobre os textos-base das campanhas da fraternidade de 1979 e 2011.

Dissertação (Mestrado). Programa de Mestrado em Desenvolvimento Regional e Meio Ambiente, Centro Universitário de Araraquara - UNIARA, 2012.

PAULO VI. Gaudium et Spes: AIgreja no mundo atual.1965. www.vatican.va

. Carta Encíclica Populorum Progressio.

26/03/1967. www.vatican.va

\section{Carta Apostólica Octogèsima}

Adveniens. 14/05/1971. www.vatican.va

. Mensagem à Conferência sobre Meio

Ambiente de Stockolm: As preocupações

ecológicas e as exigências do desenvolvimento.

Roma: Osservatore Romano, 18/06/1972.

\section{. Mensagem à Conferência da $\mathrm{ONU}$} sobre Meio Ambiente em Vancouver: Uma política do "habitat" humano para o desenvolvimento integral do homem. Roma: Osservatore Romano. 13/ 06/1976.

PRATES, L. Fraternidade libertadora: uma leitura histórico-teológica das Campanhas da Fraternidade da Igreja no Brasil. São Paulo: Paulinas, 2007.

RIBEIRO, M. A. Caminhos para uma cultura da paz com a natureza. In: MAGALHÃES, D. (org.) A paz como caminho. Rio de Janeiro: Qualitymark, 2006.

TOMKO, J. Lineamenta para o Sínodo dos Bispos de 1983. 28/01/1982. www.vatican.va

TRIGUEIRO, A. (coord.). Meio ambiente no século 21: 21 especialistas falam da questão ambiental nas suas áreas de conhecimento.Campinas:Armazém do Ipê, 2005.

ReCEBIDO EM 22/4/2014

Aсеiтo ем 22/9/2014 